\title{
ANALYSIS OF OLDER PEDESTRIAN ACCIDENTS: A CASE STUDY OF LITHUANIA
}

\author{
VILMA JASIŪNIENE ${ }^{1 *}$, DONATAS ČYGAS ${ }^{2}$ \\ ${ }^{1}$ Road Research Institute, Vilnius Gediminas Technical University, \\ Vilnius, Lithuania \\ ${ }^{2}$ Dept of Road, Vilnius Gediminas Technical University, \\ Vilnius, Lithuania
}

Received 22 October 2019; accepted 9 December 2019

\begin{abstract}
However, for several decades, Europe has been witnessing demographic ageing. As a result of these changes, a more significant number of elderly road users will be involved in future traffic, and therefore safe mobility management of the older will become an increasingly important issue. Various physical, sensory, and cognitive constraints affecting elderly road users lead to a rise in the likelihood of an accident, which, due to the increased physical vulnerability, cause more serious consequences of road accidents. The findings reported by the authors of an in-depth analysis of accidents for four years have demonstrated that the risk of road fatalities for elderly road users is by one fifth more significant than the average of all age groups, and the pedestrian plays the most critical role in road traffic. To adequately compensate for the observed age-related physiological changes, the authors discuss actions and road safety measures to ensure appropriate conditions for older pedestrians on the streets.
\end{abstract}

Keywords: accidents, demographic change, elderly road users, mobility, pedestrians, road safety, roads, streets.

\footnotetext{
* Corresponding author. E-mail: vilma.jasiuniene@vgtu.lt

Vilma JASIŪNIENÉ (ORCID ID 0000-0002-6093-2825)

Donatas ČYGAS (ORCID ID 0000-0001-5789-1981)

Copyright (C) 2020 The Author(s). Published by RTU Press

This is an Open Access article distributed under the terms of the Creative Commons Attribution License (http://creativecommons.org/licenses/by/4.0/), which permits unrestricted use, distribution, and reproduction in any medium, provided the original author and source are credited.
} 


\section{Introduction}

However, for several decades, Europe has been witnessing demographic ageing, i.e. variations in population age characterised by the increasing numbers of older people or a decrease in young people. The old-age dependency ratio (people aged 65+ relative to those aged 15 to 64 ) in the European Union (EU) is projected to increase by 21.6\%, from 29.6\% in 2016 to $51.2 \%$ in 2070 (European Commission Directorate..., 2018). The 2018 Ageing Report (European Commission Directorate..., 2018) on population pyramids show that in keeping to the 2015-based population projections, the structure of the EU and euro-area populations is expected to age significantly (Figure 1). It is noteworthy that the significant ageing of the population over 80 is observed and has risen by $14 \%$.

Life expectancy is undoubtedly one of the most promising human success stories reflecting advances in medicine, education, and economic development (Skučienè, Bartkus, Moskvina, \& Uleckienè, 2015). However, the ageing population also poses challenges to the national economy, labour market, health care, social support, mobility, and other systems.

As a result of demographic changes, increasingly older people will actively take part in future traffic. A more significant part of elderly road users aged 65+ will significantly increase the risk of being involved in the road accident for the representatives of this age group. As reported by Polders, Vlahogianni, Leopold, \& Durso (2015), at the moment one road fatality out of five is aged 65 or over in Europe, and

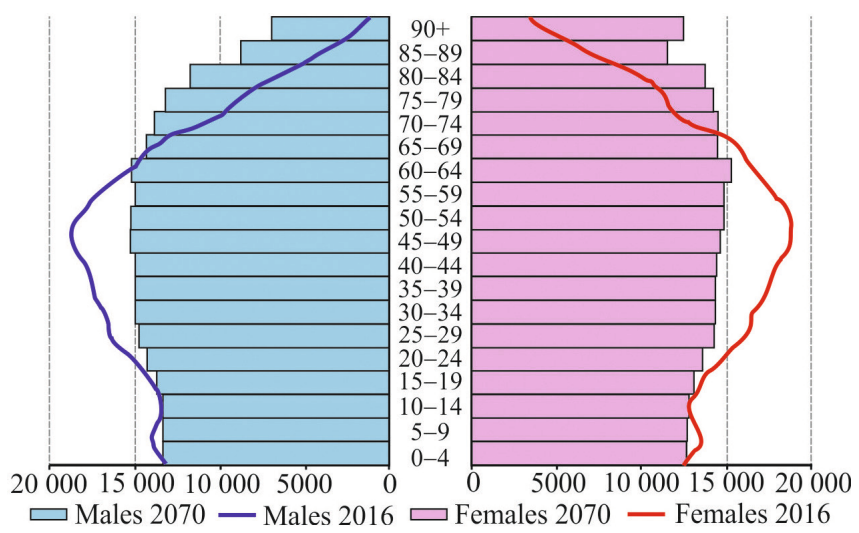

Figure 1. Population by age group and gender for the period 2016-2070 (European Commission Directorate..., 2018) 

three will be an older person in the case the risk rates of older people and younger age groups decline at the same pace. Thus, by 2050 , the share of older people road fatalities will have increased by $13 \%$.

Indeed, the mobility of elderly road users is to be encouraged as it affects the quality of life. Mobility provides older people with independence, the possibility of access to social events and living life to the fullest (Duim, Lebrão, \& Antunes, 2017; Marin-Lamelleta \& Haustein, 2015). The analysis carried out in Austria (Daniel, Pokriefke, \& Risser, 2013) shows that most older people travel daily (Figure 2), and thus a discussion on how to ensure safer traffic conditions for this group of road users is very relevant.

To ensure the safe mobility of elderly road users aged 65+, assessing their age-related physiological changes is required. Various physical, sensory, and cognitive constraints influencing elderly road users affect safe involvement in traffic (Kim, 2019). Reduced eyesight, hearing and mobility are the most significant contributors to safe traffic. Figure 3 presents the results of the study conducted in the Netherlands and shows changes in the abilities mentioned above by age group. The critical point is that a serious sudden deterioration in the groups of people aged $80+$ is noticed. These are namely the age groups in which, as noted above, a remarkable rise in the number of people is witnessed. The changes listed increase the likelihood of an accident and have more serious consequences due to the greater physical fragility of elderly road users.

The article is aimed at conducting an in-depth analysis of road accidents that involved road users aged 65+ in Lithuania, at identifying the most dangerous places and conditions for elderly road users and at providing a possibility of discussing the most appropriate road safety

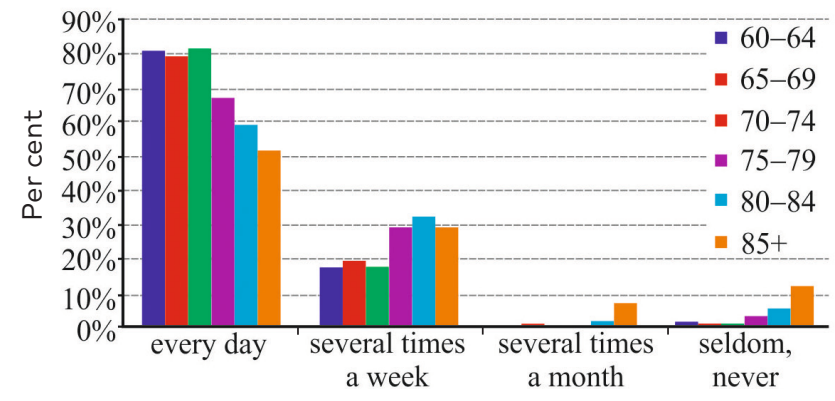

Figure 2. The frequency of leaving home by age group, Austria (Daniel, Pokriefke, \& Risser, 2013) 


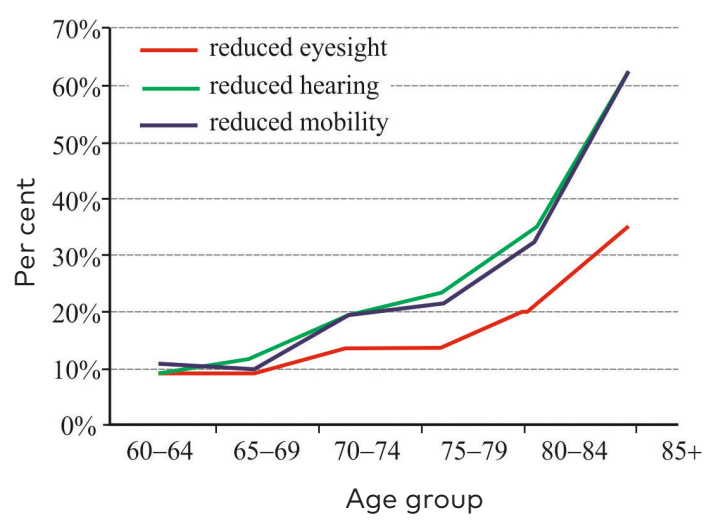

Figure 3. Physical impairment, Netherlands (Daniel, Pokriefke, \& Risser, 2013)

activities and measures. In the next stage of this study, the behaviour of road users is planned to be investigated in the most dangerous locations identified during this study.

\section{Data and methods}

\subsection{Data}

For an in-depth analysis of road accidents that involved road users aged 65+, accident data recorded by the police for the period 2015-2018 have been used. Similarly, to most countries, police accident reports are the primary source for official data in Lithuania. These reports usually contain information on road user characteristics, road accident consequences, traffic conditions, vehicle performance, and road environment. Data on urban and rural resident population by age taken from Statistics Lithuania have been employed to calculate relative indexes.

\subsection{Characteristics of the case study}

At the beginning of 2019, the population of Lithuania consisted of 2794184 (Statistics Lithuania). The people aged 65+ represent $19.77 \%$ of the total population, $67.02 \%$ of which live in the urban and $32.98 \%$ in the rural area. Although an insignificant increase in the population aged $65+$ has been observed in Lithuania over the past decade, however, the age group of no less than 85 stands out markedly. This age group has grown as much as $62.70 \%$ in the recent ten years. 
The analysis of accident statistics over the past ten years shows Pedestrian Accidents: a Case Study of Lithuania that significant results have been achieved in reducing accident rates in Lithuania, which makes 111 fatalities per 1 million inhabitants in 2009 to 61 fatalities per 1 million inhabitants in 2018. However, taking into account the examined accident statistics, the article addresses the issue of observing an increase in the percentage of road users aged $65+$, i.e. in 2009 , road fatalities of the investigated age group accounted for $18 \%$ of all road fatalities that year whereas in 2018 it amounted to $25 \%$, which is the group of road users counting the largest number of mortality compared to other age groups.

\subsection{Methods}

Road accident analysis has been made using accident analysis system ONHA LT created together with the scientists from Vilnius Gediminas Technical University, Technical Research Centre VTT of Finland, and Lithuanian Road Administration. The main objective of ONHA LT is to create the possibility for a user to study accident data in different layers. ONHA LT has been developed to analyse the number of accidents and their consequences, the circumstances of accidents and their locations, parties and persons involved in them (Jasiūnienè, Ratkevičiūtè, \& Peltola, 2019). ONHA LT combines three databases of road accidents:

- database of road users involved in accidents;

- database of vehicles involved;

- database of conditions during the accident (road surface, weather, time, place, and other).

The ONHA LT database includes all information about road accidents on Lithuanian roads and streets for the period 2010-2018.

\section{Results and recommendations}

This chapter provides a detailed statistical analysis of road accidents involving road users aged 65+ with the primary objective of identifying the most dangerous traffic conditions for the participants of this age group. Accident data collected for the period 2015-2018 have been used for analysis.

For the period 2015-2018, 200 road users aged 65+ were killed and 2041 were injured on Lithuanian roads and streets, which makes $25.25 \%$ of all fatalities and $13.51 \%$ of all injured. A similar trend is observed in the European Union, where $28 \%$ of road fatalities were pedestrians aged $65+$ (European Commission, 2019). Lithuanian economy exceeded than 
EUR 101 million losses caused by the fatalities of road users aged $65+$ for the period 2015-2018.

Figure 4 shows a chart illustrating the number of road fatalities and injuries per 1 million inhabitants in different age groups in Lithuania for 2018. The risk of elderly road users aged $65+$ is by $20 \%$ higher to be killed in an accident than the average of all age groups, which is closely related to the age-related physiological changes because elderly road users have a disproportionate injury risk. Increased physical fragility is the result of the normal ageing process (Polders, Vlahogianni, Leopold, \& Durso, 2015). Although the risk of injury is lower than the average of all age groups in the group of road users aged $65+$, due to the above-mentioned physiological changes in the elderly, a more extended recovery period is typical of them. Moreover, fractures in both curves are observed at the age of 75 to 79. The research literature provides that the age of 75 appears to be a turning point since the mobility of the older respondents decreases markedly around this time of life. Most probably, the exhibited decrease is related to the fact that health issues and impairments are prevalent with the rising age (Polders, Vlahogianni, Leopold, \& Durso, 2015). A drastic increase in the rate of fatalities is related to fragility growing along with age. The bones of elderly road users are more brittle and soft tissue is less elastic, and hence they are at higher risk of severe injury, even when accident forces are the same (European Commission, European..., 2018).

Elderly road users are involved in traffic as drivers, passengers, or pedestrians. Accident statistics for the period 2015-2018 show that the role of the pedestrian is the most dangerous for an elderly road user

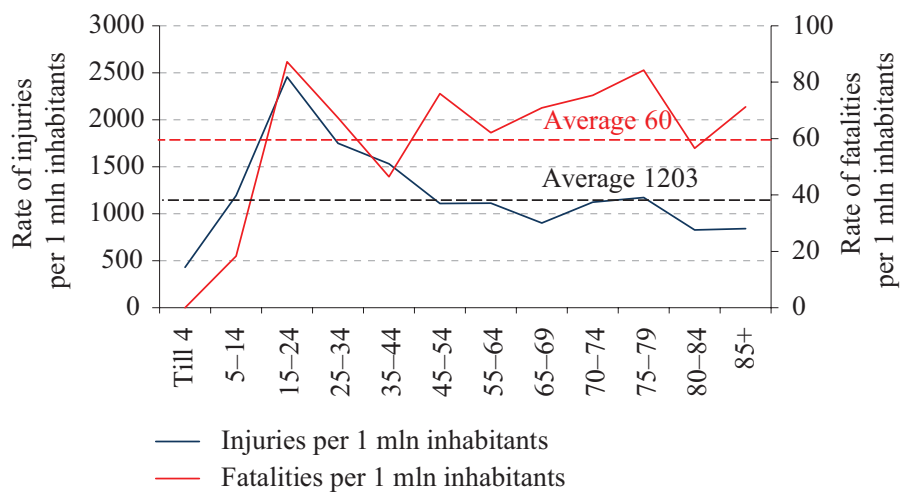

Figure 4. The rate of fatalities and injuries per 1 million inhabitants per age group in Lithuania in 2018 

and passengers made 18\% each. A very similar situation is observed in the Member States of the European Union because an increasingly ageing road user frequently turns from a driver to a pedestrian.

The analysis of accident statistics by type of accident demonstrates that elderly road users suffer most, i.e. experience fatal injuries in the running to pedestrian and collisions (Figure 6). Inline to the data obtained for the period of the past four years (2015-2018), the aboveintroduced types of fatal injuries made $53 \%$ and $26 \%$ of all road users aged $65+$, respectively.

Pedestrians are a vulnerable road user group in many European countries (Mathieson, Dean, Goss, Farthing, \& Hood, 2013). Thus, it must be emphasised that road accidents that involve older pedestrians are particularly pronounced on city streets (or in urban areas) in Lithuania. In agreement with the estimates for the period $2015-2018,72 \%$ of all traffic accidents on the streets involved 65 fatalities of running into the pedestrian.

Older pedestrians are clearly at a high-risk compared to other age groups. Accident statistics show that the risk of the road fatality for older pedestrians is 1.55 times higher than the average of all age groups, or even 2.47 times more compared to road users under 64 (Figure 7).

The above analysis points to the need to look for solutions to improve the safety of elderly road users, especially pedestrians. To encourage the studied road users to move as much as possible and to be actively involved in social life, it is necessary to address the issue of ensuring their safety. Road accident analysis related to traffic conditions to highlight the location of the problem is performed below.

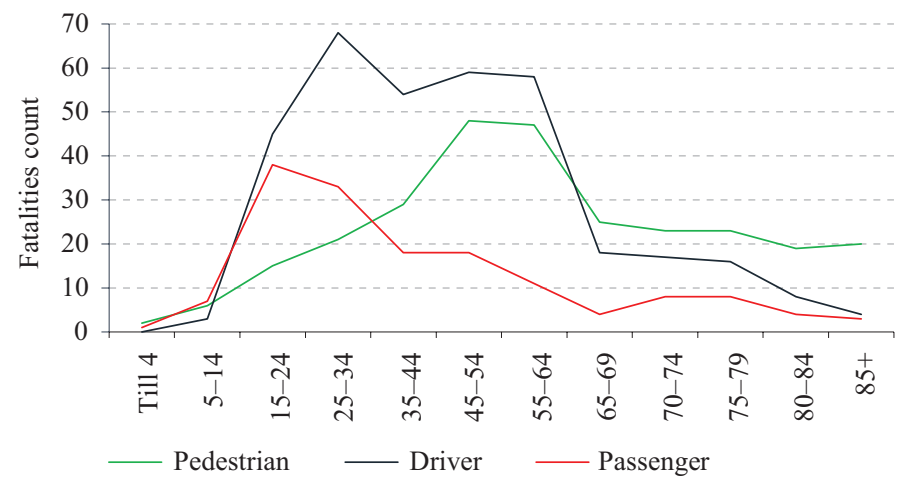

Figure 5. The distribution of road fatalities in line to the roles of road users on the streets and roads for the period 2015-2018 


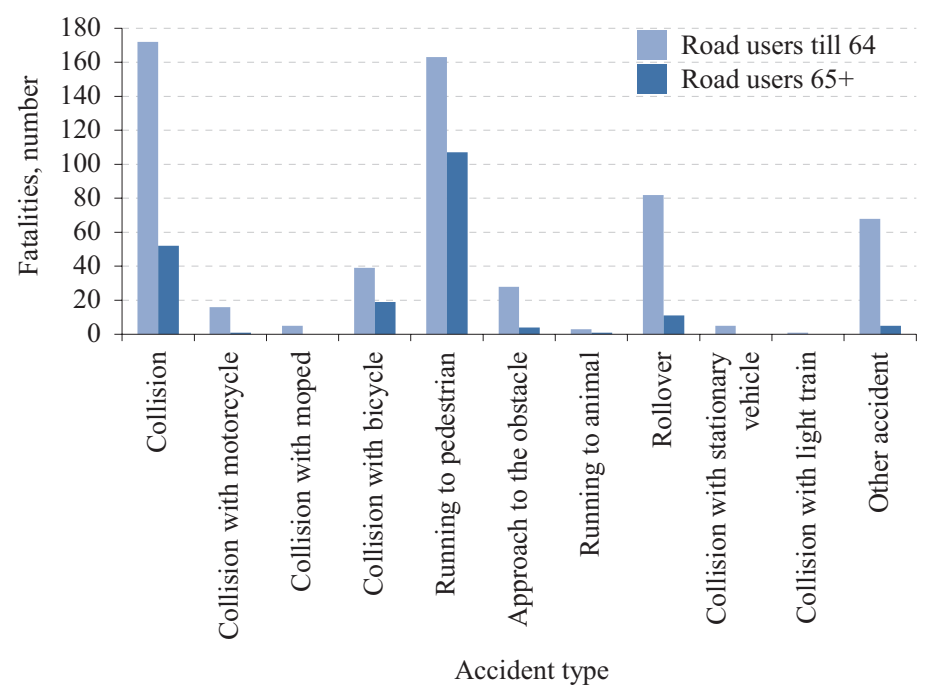

Figure 6. The distribution of road fatalities in line to road accident types on the streets and roads for the period 2015-2018

Further analysis refers to data on accidents that occurred on city streets considering a pretty large number of older pedestrians suffering from accidents on the streets of the urban area. Accident analysis in line to accident location was performed to identify the most dangerous places for older pedestrians (Figure 8). The study showed that as much

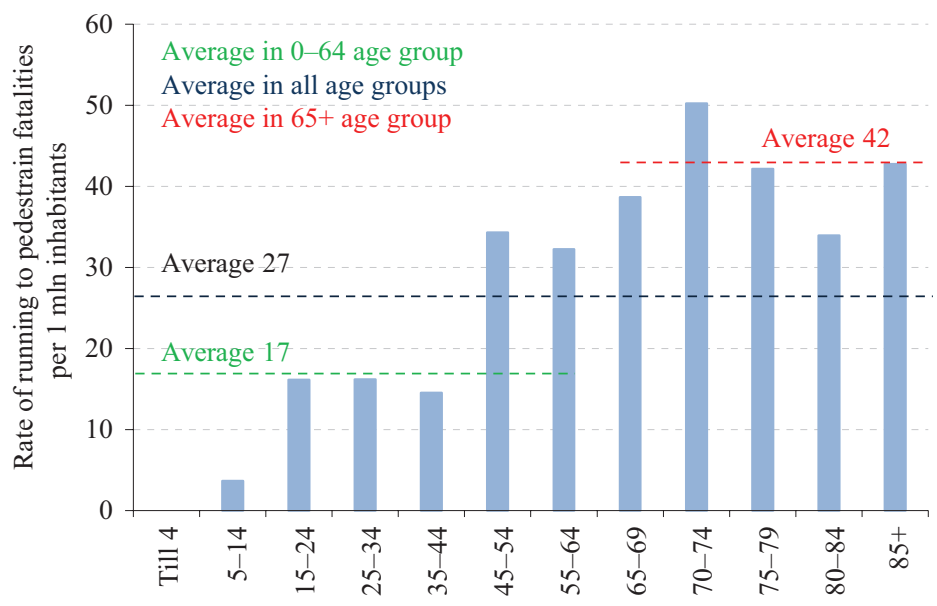

Figure 7. The rate of running to pedestrian fatalities per 1 million inhabitants per age group in Lithuania in 2018 

aged 65+ were killed while crossing the carriageway on links, 46\% crossing the street in the straight section lacking a pedestrian crossing and the rest were involved in other accident schemes.

The performed analysis disclosed that the dark time of the year was the most dangerous period for pedestrians, including elderly road users. Most accidents with pedestrians aged 65+ are observed from 4 p.m. to 9 p.m. on Friday for the period from October to February. Although the analysed road accidents occurred on city streets, $37 \%$ of fatalities took place in the areas where the lighting was turned on, and as many as $43 \%$ of pedestrians aged $65+$ died in the areas that lacked installed lighting, or this variable failed to be recorded at the time of the accident.

A summary of the accidents mentioned above with elderly road users demonstrates this group of road users is most suffer from being pedestrians and crossing the carriageway in the straight section of the street rather than the pedestrian crossing.

The analysis of accident statistics shows that it is appropriate to apply integrated road safety measures, including engineering, education and training programs and control to improve the safety of older pedestrians. The human factor is the most common problem causing accidents, and therefore continual education and frequent enforcement of older pedestrians must be the priority tools for improving road safety when dealing with pedestrian traffic at non-pedestrian crossings in particular.

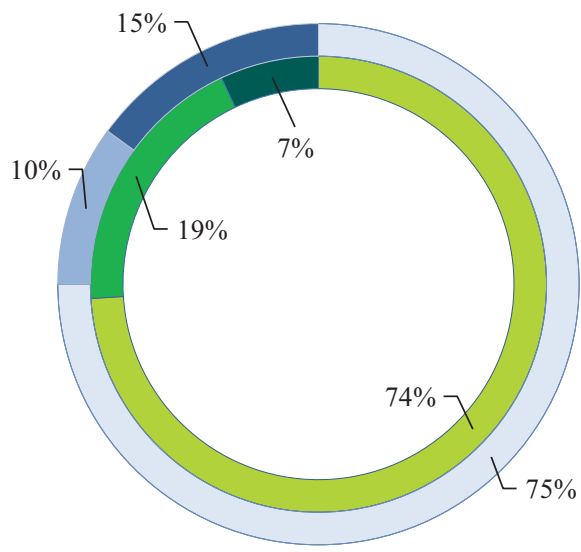

Fatalities on link

Fatalities on junction regulated by traffic signs

Fatalities on junction regulated by traffic lights

Injuries on link

Injuries on junction regulated by traffic signs

Injuries on junction regulated by traffic lights

Figure 8. The distribution of fatalities and injuries caused by older pedestrians considering the road accident location 
Road infrastructure must be designed for road users of all ages and mobility opportunities. Due to the observed demographic ageing, the increasing proportion of older road users in traffic and a higher risk of leading to more serious consequences of accidents than those experienced by younger road users, designing roads and streets must provide solutions that effectively ensure the safety of older road users.

Crossing the carriageway is a rather complex task for older pedestrians and requires assessing the surrounding traffic situation, deciding, and acting (Dommes, 2019). Considering the age-related physiological changes described above, the safe crossing of the carriageway becomes a challenge. Figure 7 shows the distribution of fatalities and injuries by accident location and illustrates that crossing the carriageway at the non-pedestrian crossing, i.e. at the places hardly intended for crossing the carriageway or at the access to pedestrian crossings is a particularly acute problem. Furthermore, considering the detailed analysis of the specific area and accidents, installing pedestrian safety fences in these places thus guiding pedestrians towards the pedestrian crossing or analysing pedestrian flows and attraction objects, e.g. medical facilities, and churches, to arrange pedestrian crossings is recommended.

Updating design solutions are required to improve the safety of elderly road users at pedestrian crossings. First, due to reduced mobility, older pedestrians move slower. In agreement to Webb, Bell, Lacey, \& Abell (2017), only $10 \%$ of walking speeds of people aged $60+$ were fast enough to cross the road in time at pedestrian crossings in the UK and US. In this regard, it is necessary to shorten the length of the pedestrian crossing to keep pedestrians on the carriageway for a shorter time as possible. For that purpose, it is recommended to extensively use measures for traffic calming (Gonzalo-Orden, Pérez-Acebo, Unamunzaga, \& Arce, 2018) such as curb extension, choker or lane narrowing that shorten the length of the pedestrian crossing and increase pedestrian visibility at crossings. The measures mentioned above also have some impact on the driving speed of vehicles, which is one the key risk of the pedestrian. The situation is particularly relevant because visual studies have shown that several Lithuanian cities have wide streets that encourage vehicles to travel faster. Approximately $50 \%$ of drivers exceed the speed limit (Distefano \& Leonardi, 2019; Yannis, Louca, Vardaki, \& Kanellaidis, 2013). Distefano \& Leonardi (2019) identified that lane narrowing reduces the speed of vehicle flow $V_{85} 16 \mathrm{~km} / \mathrm{h}$ approximately. In agreement to the Distefano \& Leonardi (2019) of the analysis of traffic accident changes, the number of pedestrians involved in pedestrian accidents decreased by $33 \%$, and the number of pedestrians injured was reduced by $33 \%$. 
At the crossings where specific parameters, e.g. street function, a Case Study category, permissible operating speed, the composition of vehicle traffic, heavy scheduled and specific vehicle traffic, are insufficient to employ the above-introduced measures, installing pedestrian refuge islands in the middle of the carriageway is a good option. Such islands are very effective at increasing safety for pedestrians crossing the street and allow pedestrians to cross one direction of vehicle traffic at a time. Institute of Transportation Engineers (2004) determined that installing refuge islands associated with a $56 \%$ reduction in pedestrian accidents. Sadrayi, Saffarzadeh, \& Boroujerdian (2016) observed that pedestrian refuge island reduces the probability of fatal pedestrian accidents to under $10 \%$. Besides, vehicle speeds at pedestrian refuges reduce by $6 \%$. Besides, solutions for shortening the length of the pedestrian crossing are also useful for reducing the risk of pedestrian falls caused by the rush to cross the street. Ewert (2012) notes that older pedestrians are afraid of falling, they mostly look to the ground when crossing and as such pay less attention to surrounding traffic. An integrated set of conditions leading to critical conditions for pedestrian traffic at crossings is observed considering the factors listed above.

The lighting of pedestrian crossings significantly affects pedestrian safety. Older pedestrians also tend to wear dark clothes, especially in winter, which reduces their visibility (Oxley, Corben, Fildes, \& Charlton, 2004). Moreover, the use of reflectors has barely become the norm. Uttley \& Fotios (2017) investigated the effect of ambient light condition on road traffic collisions involving pedestrians on pedestrian crossings and found out that one of the purposes of a pedestrian crossing was to make the presence of a pedestrian and the likelihood of them crossing the road more conspicuous to the driver. It is necessary to alert the driver to the fact they are approaching a designated crossing and making any pedestrian stood at or on the crossing visible to the driver. Retting, Ferguson, \& McCartt (2003) reviewed the effects of several traffic engineering measures in pedestrian safety and concluded that intense lighting at crossings was related to significant reductions in pedestrian crashes at night time. Retting, Ferguson, \& McCartt (2003) study, conducted in Australia, reported a 59\% reduction in pedestrian crashes following improvement in roadway lighting. Bearing in mind that most traffic accidents with pedestrians aged 65+ occurred in the dark period of the day in Lithuania, priority must be given to the installation of directional lighting.

Educational activities are also essential for solving the safety problems of older pedestrians. In addition to road safety campaigns taking place in the public area, the adult children (or even grandchildren) play a crucial role. They have to be proactive in reminding pedestrians 
aged 65+ about the risks arising on the street, informing them of changes in road traffic regulations and control, introducing safer routes to the most visited sites.

\section{Conclusions}

1. Lithuania, as well as other European Union countries, face significant growth in the number of older people. Those aged $85+$ stand out remarkably well because their number has risen to $62.70 \%$ over the recent decade. As a result of the above-mentioned demographic changes, the growing number of older pedestrians aged $65+$ will be involved in future traffic. Thus, due to their agerelated physiological changes, the likelihood of an accident will markedly increase, and owing to the higher physical fragility of elderly road users, more severe consequences of accidents are expected.

2. A detailed analysis of accidents shows that one road traffic fatality out of four is aged 65+ in Lithuania. The risk of road traffic fatality of road users in this age group (65+) is $20 \%$ higher than the average of the rest of the age groups. The role of the pedestrian is the most dangerous for an older road user, particularly on city streets. Running to pedestrian made as many as $72 \%$ of all fatalities on the streets involving road users aged 65+. The risk of road fatality for older pedestrians is 1.55 times higher than the average of all age groups, or even 2.47 times more compared to road users under 64.

3. The extensive use of appropriate road safety management solutions is required to improve traffic conditions for older pedestrians and thus to encourage their mobility, in addition to educational activities and control measures. One of the crucial decisions involves shortening the length of the pedestrian crossing, widely employing various traffic calming measures that assist in partially compensating for the impaired eyesight, hearing and mobility of older pedestrians and in reducing the driving speed of vehicles, which allows the driver to easier detect the pedestrian and mitigate the faced consequences in the event of an accident. 


\section{REFERENCES}

Daniel, B., Pokriefke, E., \& Risser, R. (2013). Road safety in the ageing societiesCONcerns and SOLutions.

Distefano, N., \& Leonardi, S. (2019). Evaluation of the benefits of traffic calming on vehicle speed reduction. Civil Engineering and Architecture, 7(4), 200-214. https://doi.org/10.13189/cea.2019.070403

Dommes, A. (2019). Street-crossing workload in young and older pedestrians. Accident Analysis \& Prevention, 128, 175-184. https://doi.org/10.1016/j.aap.2019.04.018

Duim, E., Lebrão, M. L., \& Antunes, J. L. F. (2017). Walking speed of older people and pedestrian crossing time. Journal of Transport \& Health, 5, 70-76. https://doi.org/10.1016/j.jth.2017.02.001

European Commission (2019). 2018 road safety statistics: what is behind the figures?

European Commission Directorate-General for Economic and Financial Affairs (2018). The 2018 Ageing Report. Economic \& Budgetary Projections for the 28 EU Member States (2016-2070). 406 p.

European Commission, European Road Safety Observatory (2018). Pedestrians and Cyclists 2018. Report. $44 \mathrm{p}$.

Ewert, U. (2012). Faktenblatt Senioren als Fussgänger. Bern: BFU. (in German)

Gonzalo-Orden, H., Pérez-Acebo, H., Unamunzaga, A. L., \& Arce, M. R. (2018). Effects of traffic calming measures in different urban areas. Transportation research procedia, 33, 83-90. https://doi.org/10.1016/j.trpro.2018.10.079

Institute of Transportation Engineers (2004). Toolbox of Countermeasures and Their Potential Effectiveness to Make Intersections Safer. Briefing Sheet 8, FHWA.

Jasiūnienè, V., Ratkevičiūtė, K., \& Peltola H. (2019). Road Network Safety Ranking Using Accident Prediction Models. In: Varhelyi, A., Žuraulis V., Prentkovskis 0. (eds). Vision Zero for Sustainable Road Safety in Baltic Sea Region. VISZERO 2018. Lecture Notes in Intelligent Transportation and Infrastructure. Springer, Cham (pp. 166-176).

Kim, D. (2019). The transportation safety of elderly pedestrians: Modeling contributing factors to elderly pedestrian collisions. Accident Analysis \& Prevention, 131, 268-274. https://doi.org/10.1016/j.aap.2019.07.009

Marin-Lamelleta, C., \& Haustein, S. (2015). Managing the safe mobility of older road users: How to cope with their diversity?. Journal of Transport \& Health, 2, 22-31. https://doi.org/10.1016/j.jth.2014.07.006

Mathieson, P., Dean, A., Goss, S., Farthing, D., \& Hood, J. (2013). SaMERU-Safer mobility for elderly road users.

Oxley, J., Corben, B., Fildes, B., \& Charlton, J. (2004, November). Older pedestrians: Meeting their safety and mobility needs. In Proceedings of the Road Safety Research, Policing and Education Conference, Perth, Australia (pp. 14-16).

Polders, E., Vlahogianni, E., Leopold, F., \& Durso, C. (2015). ElderSafe-Risks and countermeasures for road traffic of elderly in Europe (No. MOVE/ 
C4/2014-244). Brussels: European Commission-Directorate-General for mobility and transport (DG-MOVE).

Retting, R. A., Ferguson, S. A., \& McCartt, A. T. (2003). A review of evidence-based traffic engineering measures designed to reduce pedestrian-motor vehicle crashes. American Journal of Public Health, 93(9), 1456-1463. https://doi.org/10.2105/ajph.93.9.1456

Sadrayi, A., Saffarzadeh, M., \& Boroujerdian, A. M. (2016). An assessment of the impact of pedestrian refuge islands on vehicle speed changes and pedestrian safety: case study in Tehran. International journal of transportation engineering, 3(4), 289-300. https://doi.org/10.22119/ijte.2016.16180

Skučienè, D., Bartkus, A., Moskvina, J., \& Uleckienė, A. (2015). Senéjanti visuomené: Kaip mes pasirengę. Lietuvos socialinių tyrimų centras. 332 p. (in Lithuanian)

Uttley, J., \& Fotios, S. (2017). The effect of ambient light condition on road traffic collisions involving pedestrians on pedestrian crossings. Accident Analysis \& Prevention, 108, 189-200. https://doi.org/10.1016/j.aap.2017.09.005

Webb, E. A., Bell, S., Lacey, R. E., \& Abell, J. G. (2017). Crossing the road in time: Inequalities in older people's walking speeds. Journal of Transport \& Health, 5, 77-83. https://doi.org/10.1016/j.jth.2017.02.009

Yannis, G.; Louca, G.; Vardaki, S.; Kanellaidis, G. (2013). Why do drivers exceed speed limits? European Transport Research Review, 5(3), 165-177.

https://doi.org/10.1007/s12544-013-0097-x 